\title{
THE POTENTIAL FOR EVOLUTION OF HEAVY METAL TOLERANCE IN PLANTS
}

\author{
I. COPPER AND ZINC TOLERANCE \\ IN AGROSTIS TENUIS
}

\author{
K. A. WALLEY, M. S. I. KHAN* and A. D. BRADSHAW† \\ School of Plant Biology, University College of N. Woles, Bangor
}

Received 1.vi.73

\begin{abstract}
Summary
A simple method of screening populations for the occurrence of metal tolerance was achieved by sowing seed samples on toxic formed by mixing metalliferous waste with a certain amount of ordinary potting soil: after 3-6 months tolerant individuals can easily be distinguished by their continuing growth whereas nontolerant individuals will have died.

Using this technique it was found that:
\end{abstract}

(i) Normal non-tolerant populations of the grass Agrostis tenuis contain a low frequency, 1-2 per cent, of individuals which survive on slightly ameliorated copper soil. Tests showed that some of these individuals have copper tolerances approaching those of fully tolerant populations.

(ii) The same occurred when populations were screened on zinc soil: but no survivors were found which had full zinc tolerance.

(iii) When already copper-tolerant seed was sown on zinc soil it behaved rather like non-tolerant seed. The survivors were shown to be both copper and zinc tolerant. This together with experiments on soil containing two metals indicates that tolerances to different metals are independent.

(iv) In all experiments individuals with a wide range of different tolerances could be found, and the number of survivors varied inversely with the amount of metal in the soil. This indicates that metal tolerance must be a continuously varying character with a threshold.

(v) It was concluded that high selection pressure acting on large populations can pick out rare gene combinations and change the characteristics of populations in a spectacular manner.

\section{INTRODUCTION}

THE occurrence of heavy metal tolerance in populations of many plant species found on metal contaminated soils is now well established (see Antonovics, Bradshaw and Turner, 1971 for review). It raises the problem of its origin and the specific part played by natural selection in its appearance and retention. Jowett (1964), McNeilly and Bradshaw (1968), and others have found some indication of metal tolerant individuals in normal populations. Is this variability on which selection can readily act to produce metal tolerant populations?

To investigate this, the late K. A. Walley, following an unpublished experiment of Abbot and Misir, developed a simple technique by which large numbers of seed could be screened for copper tolerance by allowing

* Present address: Radiation Genetics Institute, Lyallpur, Pakistan.

$\dagger$ Present address: Department of Botany, University of Liverpool. 
them to germinate and grow for 3-6 months on toxic waste soil which had been ameliorated by the addition of $\frac{1}{12}$ by volume of potting soil. In normal populations a very few individuals (about 0.2 per cent) survived after 6 months (fig. 1). He concluded that these were copper tolerant.

Two of us (M.S.I.K. and A.D.B.) have continued with his technique to confirm that metal tolerance is present in ordinary populations of Agrostis

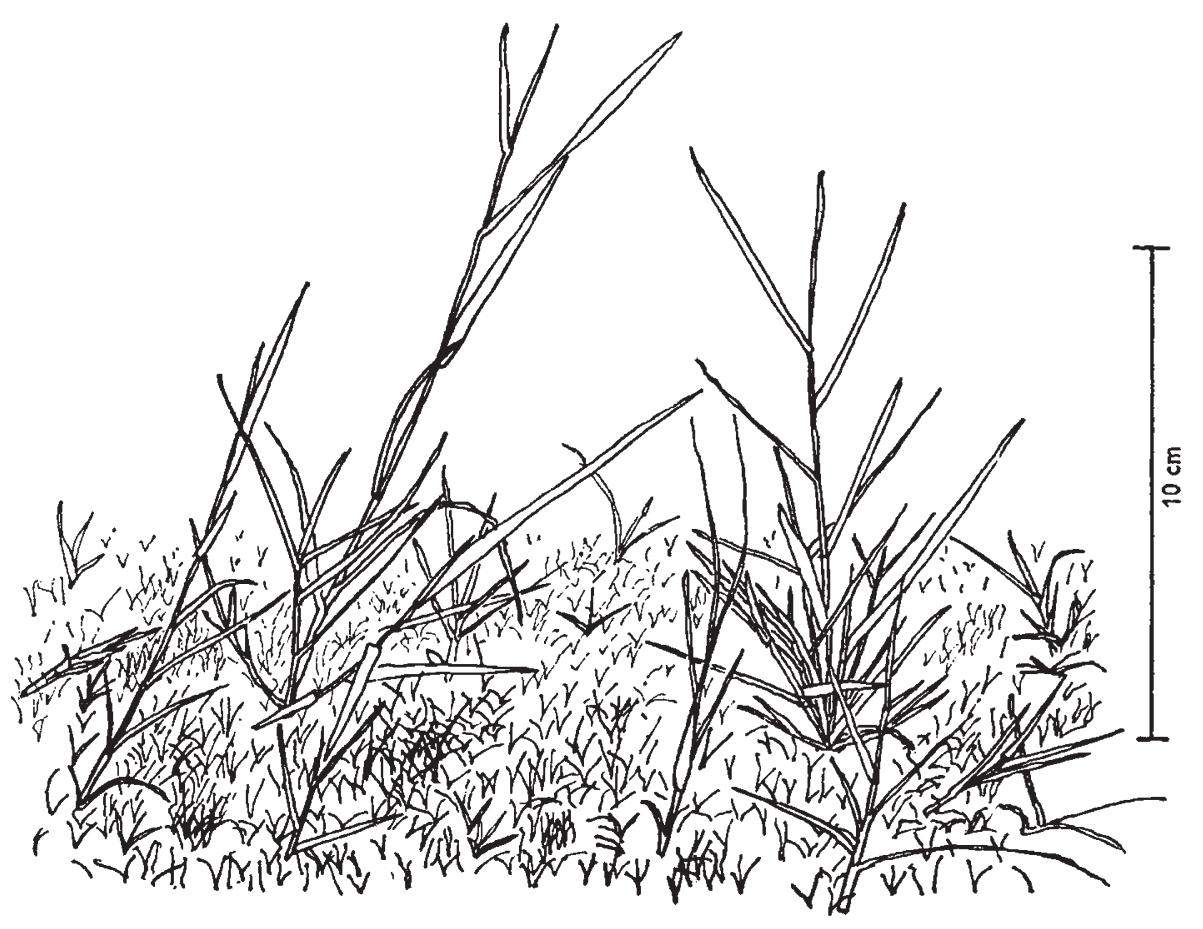

Frg. 1.-Seedlings of a normal population of Agrostis tenuis after 6 months' growth on a $12: 1$ copper waste/soil mixture: only the few large individuals are alive (drawn from a photograph of $\mathrm{K}$. Walley's material).

tenuis Sibth. and to see how easily it can be selected. Since Agrostis tenuis can evolve races tolerant to different heavy metals (Gregory and Bradshaw, 1965) we have looked at selection on both zinc and copper contaminated soils.

\section{Methods}

(i) Soil screening

Tests were carried out on copper contaminated waste from Parys Mountain, Anglesey, Wales and on zinc contaminated waste from Trelogan, Flintshire, Wales (analysis: table 1). Unfortunately it transpired that both wastes also contained lead in amounts that could make it a common selective factor to all experiments. Lead, however, is not as toxic as copper and zinc (Jowett, 1958), and although its possible selective effects cannot be disregarded, its presence, for the purposes of the experiments, can be ignored since its presence does not alter the essential findings of the experiments. 
The wastes were already finely ground. They were sterilised for 48 hours at $80^{\circ} \mathrm{C}$. They were then mixed very thoroughly with various proportions of a standard potting soil (John Innes No. 1). All mixtures also contained 25 per cent sand to assist drainage. All experiments were in $10-\mathrm{cm}$ plastic pots in a greenhouse with extra illumination in the winter. There were two replicates. Seed was sown on the surface, 1000 seeds (estimated by weight following germination test) to each pot. During germination, all pots were covered with polythene sheeting to reduce drying out. Watering was from below, and throughout the experiment the pots were screened from direct sunlight by thin cloth, as experience had shown that sunlight and high temperature in the greenhouse tended to cause early death of the plants.

TABLE 1

Analysis of copper and zinc contaminated wastes used for screening purposes (values in p.p.m.).

$\begin{array}{lccr} & \text { Copper } & \text { Lead } & \text { Zinc } \\ \text { Parys Mountain } & 1195 & 1065 & 185 \\ \text { Trelogan } & 70 & 4950 & 38060\end{array}$

At the end of the experiment 100 seedlings were picked at random from each pot and measured for various characters.

\section{(ii) Tolerance tests}

Seedlings for which tolerance values were required were removed from the metal soils and grown on in ordinary soil for at least 3 months, during which time they were divided and replanted into new soil as necessary, at least every 2 months, until testing.

Tillers were then taken and tested for tolerance in the normal manner (Jowett, 1958; Antonovics, Bradshaw and Turner, 1971), by the parallel technique in which the tillers of each genotype were allowed to root in a solution containing hydrated calcium nitrate $(0.5 \mathrm{~g} / 1)$ while an equal number of tillers were allowed to root in a similar solution to which the appropriate heavy metal had been added. The ratio of length of longest root in metal containing solution to length of longest root in solution containing only calcium nitrate gave the index of tolerance. The solutions were changed every 2 days. For each genotype in a particular solution there were 20 tillers divided between 2 replicates. The tests were performed in a small growth cabinet maintaining 100 per cent humidity and $25^{\circ} \mathrm{C}$. with continuous illumination at $5000 \mathrm{~lx}$.

\section{(iii) Seed material}

The main source of normal non-tolerant material was a single sample of commercial Agrostis tenuis from New Zealand, supplied by Messrs Gartons. This comes from poor acid pastures containing only trace levels of heavy metals: the Agrostis tenuis came originally from England either in hay or in seed samples. For comparison seed material from natural populations growing on mine waste at Parys Mountain and at Trelogan, known to be copper and zinc tolerant respectively, was also used. 


\section{Sareening For copper tolerance (experiment 1)}

Seeds of normal and copper mine populations of Agrostis tenuis were grown on a range of copper waste/soil mixtures of different copper content in a randomised block arrangement with two replicates, over a 4-month winter period. There was a very marked effect of copper on germination, which was greater on the normal than on the mine population (fig. 2). As the experiment progressed, the numbers of individuals remaining alive decreased: these of course increased in size. So the distinction in size between survivors and the rest became more noticeable with time.

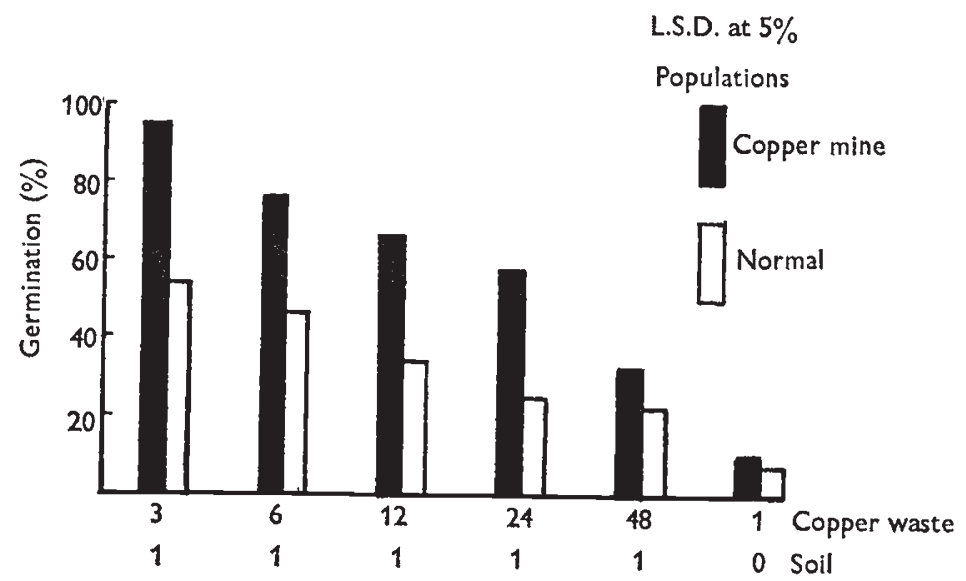

FIG. 2.-Germination of normal and copper mine populations on different copper waste/soil mixtures, as percentage of germination on normal soil.

At the end of the experiment 200 seedlings were measured. Their mean height showed a reduction with increasing amount of copper. What was more interesting was the variation in height which is shown in the histograms (fig. 3). The mean height of the mine population seedlings was markedly greater than that of the normal population seedlings, but within the normal population seedlings there were a few individuals of considerable height equal to or greater than the mine seedlings.

Examination of the normal population material showed that it was nearly all dead and the seedlings which were surviving properly were only the few tall individuals. By contrast a large number of the mine population were surviving (fig. 4). Increasing copper concentration markedly reduced the numbers of survivors in both normal and copper mine populations, but particularly in the normal population. But there were a few survivors in the normal population even in the 48:1 mixture. These results duplicate Walley's earlier results. The few survivors in the non-tolerant population must be tolerant individuals, which are being readily selected by the copper containing soil. The lower frequency of survivors found by Walley can be attributed to the longer duration of his experiment.

To confirm this some of the most vigorous survivors of the non-tolerant population, from different soil mixtures were taken out and grown on in ordinary soil. At the same time a set of seedlings of the same population 


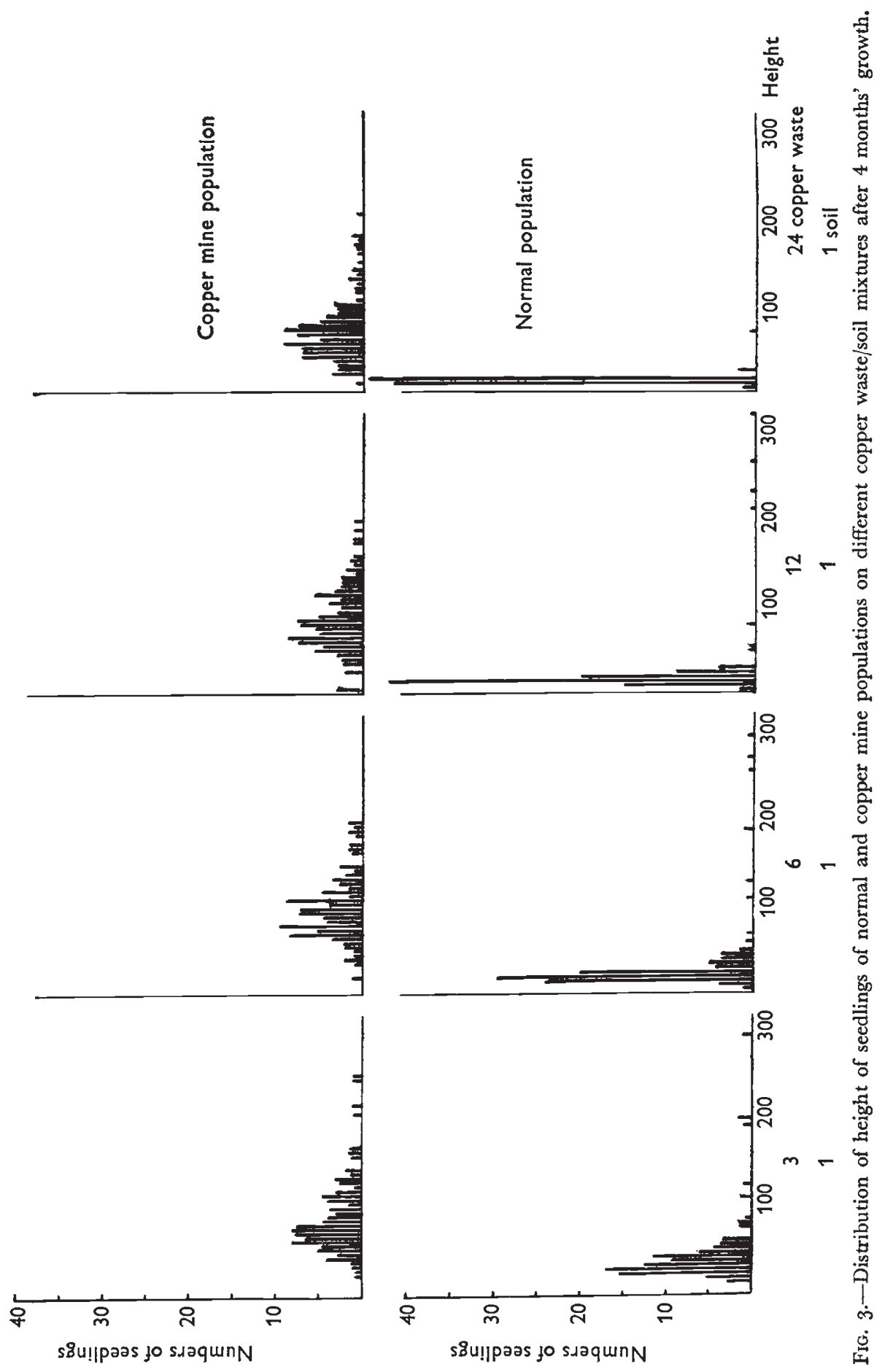


which had been grown in ordinary soil and were therefore unselected were also taken, together with material of vegetative origin of three genotypes from a local uncontaminated pasture and two from Parys Mountain as comparison. When these had been grown on for about 6 months their tolerance was tested together with some equivalent material originating from similar experiments by the late $\mathrm{K}$. Walley (table 2 ). At the same time from one soil mixture $(6: 1)$ a series of live seedlings, differing in height were also grown on. Their tolerance was also measured (fig. 5). Clearly the survivors have a tolerance which approaches that of mine material and there are a very few individuals whose tolerance may even equal it. The variation in height of the survivors correlates with their tolerance.

\section{Sareening for zing tolerance (experiments 2 and 3)}

It is now well established that Agrostis tenuis can evolve copper, lead and zinc tolerant populations (Jowett, 1958; Gregory and Bradshaw, 1965). Tolerances to these metals appear to be more or less independent of each other: it therefore seemed worth while screening normal, copper, and zinc

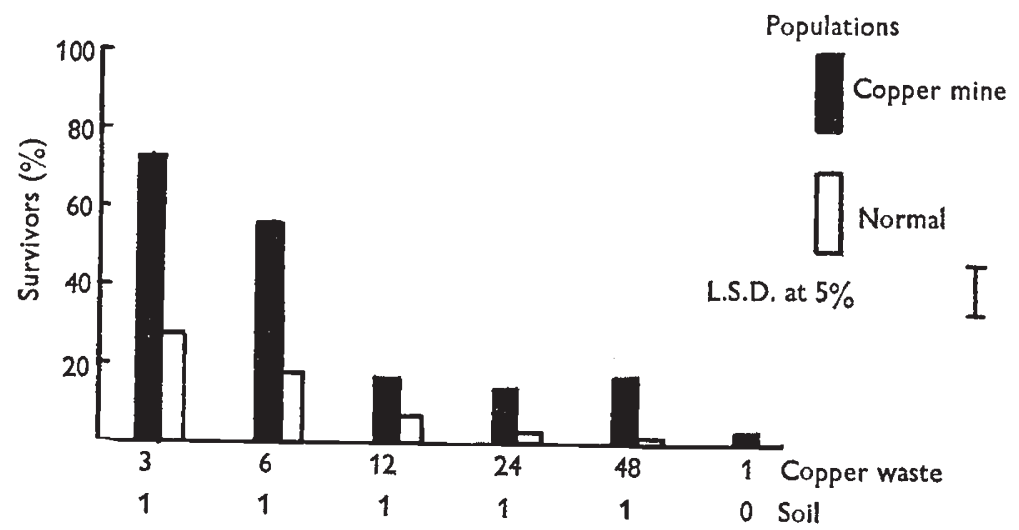

FIG. 4.-Number of survivors of normal and copper mine populations on different copper waste/soil mixtures after 4 months' growth.

tolerant populations on zinc waste/soil mixtures (experiment 3). The design of this experiment was the same as experiment 1 .

Increasing zinc had a similar but less marked effect on germination than copper. After 4 months the height of all seedlings was measured and the number of survivors was counted. The zinc soils used were not as immediately toxic as the copper soils, but this is probably because zinc is much less toxic than copper and because zinc acts on plants differently to copper (Antonovics et al., 1971). But the same pattern of results as for copper in experiment 1 was apparent, both for height (results not given) and numbers of survivors. Most of the zinc mine population seedlings were surviving at the end of the experiment and only a few of the normal population (fig. 6). The copper population appeared to take an intermediate position. There was the same sort of variation in seedling height as in the copper experiment, with the few survivors in the non-tolerant population on zinc soil showing very good growth. 
The tolerance of the survivors from this experiment was not tested. But a similar experiment (2) using the same material had been carried out previously, although it was limited, in that only two populations were available for screening on zinc soil, the normal population and the copper

TABLE 2

Copper tolerance of individual survivors from copper screening experiments compared with various other material

Normal population unselected

(seed grown on normal soil)

Normal population selected

(survivors from various copper waste/soils mixtures)

\section{Pasture population}

(individuals from a pasture)

Mine population

(individuals from a copper mine)

Normal population selected

(survivors from various copper waste/

soils mixture, K. Walley's material)

Indi

ividual
1
2
3
4
5

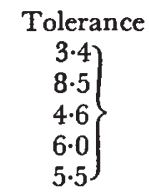

$58 \cdot 2$

$46 \cdot 1$

$46 \cdot 8$

$58 \cdot 2$

$0 \cdot 6)$

$\left.\begin{array}{l}1 \cdot 4 \\ 1 \cdot 6\end{array}\right\}$

2

1

$72 \cdot 0)$

$78.0\}$

l.s.d. (5\% prob.) $3 \cdot 7$

$\left.\begin{array}{ll}1 & 70 \cdot 8 \\ 2 & 40 \cdot 3 \\ 3 & 39 \cdot 7 \\ 4 & 19 \cdot 7 \\ 5 & 18 \cdot 5\end{array}\right\}$

1.s.d. (5\% prob.) $22 \cdot 3$

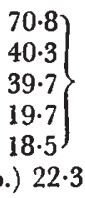

$\left.\begin{array}{l}70 \cdot 8 \\ 40 \cdot 3 \\ 39 \cdot 7 \\ 19 \cdot 7 \\ 18 \cdot 5\end{array}\right\}$
) .22 \cdot 3$

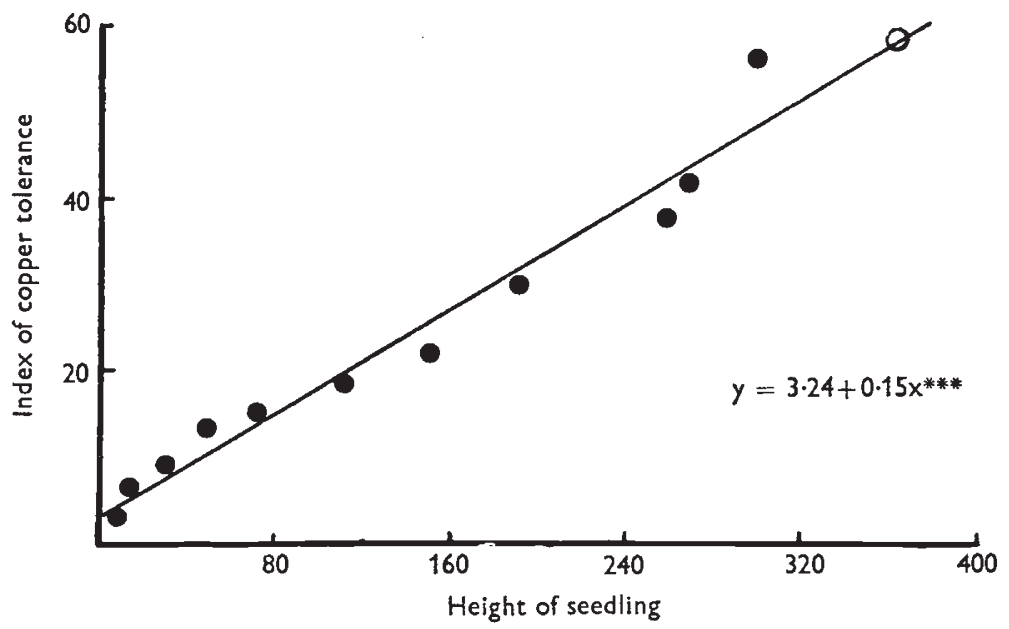

Fig. 5.-Regression of copper tolerance on height of seedling for a normal population after 4 months' growth on a 6:1 copper waste/soil mixture: $O$ is a seedling from a separate but parallel experiment. 


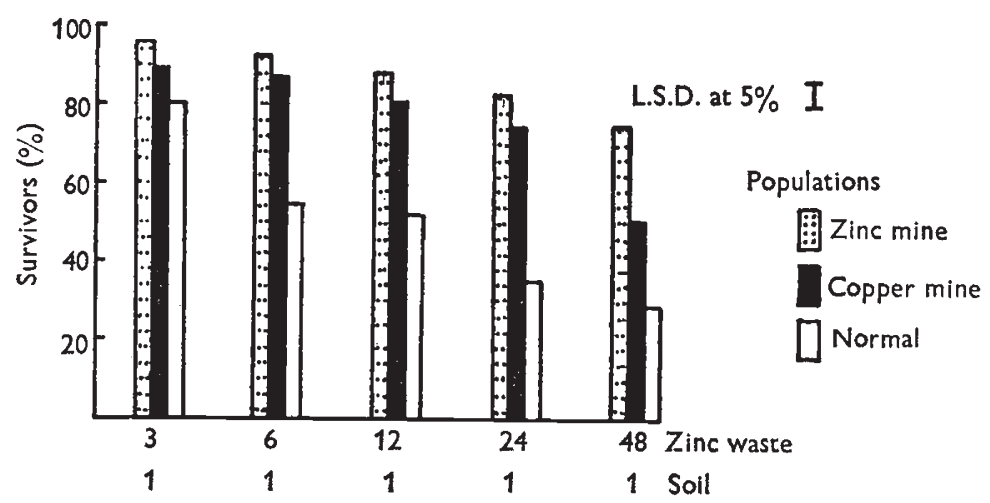

Frg. 6.-Number of survivors of normal, zinc mine, and copper mine populations on different zinc waste/soil mixtures after 4 months' growth.

mine population. Its results are therefore not reported. However, from it the most vigorous survivors were saved and grown on in ordinary soil and tested for tolerance to both zinc and copper, together with a few other genotypes from mine and pasture populations. The results (table 3) show that the survivors have marked tolerance to zinc, although not as high as can be found in a zinc mine population, and that a copper tolerant population selected for zinc tolerance may evolve zinc tolerance, at the same time retaining most of its copper tolerance.

It appears, therefore, that there is the same sort of variation in zinc tolerance as in copper tolerance in Agrostis tenuis. The screening test

TABLE 3

Zinc and copper tolerance of individval survivors from zinc screening experiments compared with various other material

Normal population selected (survivors from various zinc waste/soil mixtures)

\begin{tabular}{|c|c|c|c|c|}
\hline \multirow[b]{2}{*}{ Individual } & \multicolumn{2}{|c|}{ Tolerance } & \multicolumn{2}{|c|}{ Mean tolerance } \\
\hline & Zinc & Copper & Zinc & Copper \\
\hline 1 & $28 \cdot 6$ & $0.9)$ & & \\
\hline 2 & $41 \cdot 3$ & 0.0 & $31 \cdot 8$ & 0.3 \\
\hline 3 & $25 \cdot 6$ & $0.0)$ & & \\
\hline 1 & $47 \cdot 8$ & $49.9)$ & & \\
\hline 2 & $30 \cdot 8$ & $66 \cdot 9$ & $36 \cdot 4$ & $52 \cdot 1$ \\
\hline 3 & $30 \cdot 7$ & 43.5 & & \\
\hline 1 & 0.0 & $8 \cdot 6)$ & & \\
\hline 2 & $1 \cdot 7$ & 0.0 & 0.6 & $2 \cdot 9$ \\
\hline 3 & $0 \cdot 0$ & $0.0)$ & & \\
\hline 1 & $20 \cdot 2$ & $76 \cdot 1)$ & & \\
\hline 2 & $16 \cdot 2$ & 93.5 & $17 \cdot 6$ & $85 \cdot 3$ \\
\hline 3 & $17 \cdot 2$ & $86 \cdot 5)$ & & \\
\hline 1 & 0.8 & $87 \cdot 5$ & 0.8 & $87 \cdot 5$ \\
\hline 1 & $93 \cdot 0$ & $3 \cdot 8$ & $93 \cdot 0$ & $3 \cdot 8$ \\
\hline 1.s.d & 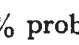 & 1 & & \\
\hline
\end{tabular}

Copper mine population selected (survivors from various zinc waste/soil mixtures)

Pasture population (individuals from a pasture)

Copper mine population unselected

(seed grown on normal soil)

Copper mine population (individual from a mine)

Zinc mine population (individual from a mine) 
suggests that copper tolerance confers some ability to survive on zinc soil. But from the tolerance test of experiment 3 it appears that zinc and copper tolerance are independent. To test the possible connection between tolerance for copper and zinc more precisely a further experiment was therefore undertaken.

\section{SGREening FOR COPPER AND zING TOleRANGe (experiment 4)}

The same three populations as in the previous experiment were used. They were sown on both copper and zinc containing soils using a ratio in both cases of 12:1 metal waste/potting soil, and on various combinations

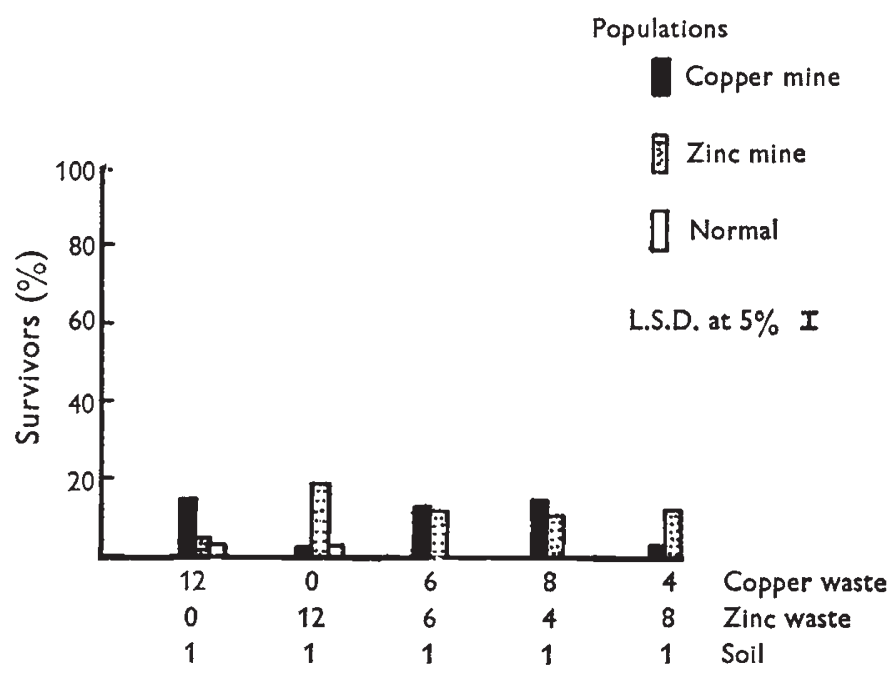

Frg. 7.-Number of survivors of normal, zinc mine, and copper mine populations on different mixtures of zinc waste, copper waste and soil after 3 months' growth.

of both zinc and copper, with the same amount of potting soil. The experiment was carried out during the summer under more extreme conditions. This perhaps explains the generally higher seedling mortality. The number of survivors after 3 months' growth (fig. 7) are very interesting. On copper soil maximum survival was shown by the copper mine population, the zinc mine population behaving like the normal population in showing a low frequency of survivors. On zinc soil, maximum survival was shown by the zinc mine population, the copper mine population behaving like the normal population. The tendency in experiment 3 of the copper mine population to have an intermediate behaviour was therefore not repeated.

On the soil made of a mixture of metals, the copper mine and the zinc mine populations gave similar responses. Here each population was subject, not only to the metal to which it was tolerant, but also to the other metal to which it was not tolerant. They should perhaps have given a response similar to that when the zinc mine populations was on copper soil or vice versa. In fact each did better than this, which can be explained by the fact that they were growing on a soil in which the metal to which they were not adapted was at 6:1 ratio and not any longer at 12:1. This is borne out by their performance on the 4:8:1 and 8:4:1 mixtures. 
Apart from this the interesting point is that the non-tolerant population did not produce any survivors when grown on the metal mixtures, although it did on the soils containing a single metal. If it is accepted from the previous evidence that tolerance to zinc and copper are independent characters, then these results can be explained if it is further assumed that the genes determining copper and zinc resistance are not linked. In these circumstances the occurrences of individuals showing both copper and zinc tolerance would be the product of the frequencies of the occurrence of each tolerance by itself. Since the latter are very small the occurrence of zinc and copper tolerance together in one individual would be so low that it could be missed by chance in an experiment of the size undertaken, in which a total of only 2000 seeds were screened on a mixture of two metals and 200 seedlings examined properly. This hypothesis needs testing by a larger experiment.

\section{Discussion}

These experiments give ample evidence that variation for copper and zinc tolerance exists in normal populations of Agrostis tenuis, and that it can easily be selected. Perhaps the particularly significant fact is that among the survivors from the copper screening experiment, individuals fully tolerant to copper can be extracted. Copper tolerance can therefore be selected from non-tolerant populations in one step, despite the evidence that copper and other metal tolerance in higher plants must be controlled by several genes (Bradshaw, McNeilly and Gregory, 1965; Urquhart, 1971). In the situations described, selection was acting on a very large number of individuals making it possible for the very few individuals possessing the appropriate combination of genes to be picked out. Agrostis tenuis is an outbreeder so a wide range of gene combinations is to be expected.

In the case of zinc, full tolerance was not achieved in one cycle of selection. Perhaps in a larger experiment fully tolerant individuals would have been found. It is possible that some selection was also occurring for lead, but this was not tested. But it will not upset the picture for copper and zinc.

In the present experiments it was not possible to test the tolerance of the offspring of the metal tolerant survivors. But the heritability of metal tolerance already reported (McNeilly and Bradshaw, 1968) and further work by Gartside and McNeilly (1974), suggests that the offspring would be tolerant.

In natural conditions selection can act on large populations and pick out very rare gene combinations. If natural selection is powerful the genetic constitution of a population could change markedly and rapidly. The rapid evolution of metal tolerance in initially ordinary populations has been demonstrated in a population at the foot of a galvanised fence by Snaydon (Bradshaw, McNeilly and Gregory, 1965) and adjacent to a copper refinery (Wu and Bradshaw, 1972). The present work gives experimental support to the possibility of extremely rapid evolution in plants. There are many other factors of the environment of plants which can exert similar powerful selection pressures. There is no reason why equivalent sorts of changes should not be able to occur in other plant species in other selective situations provided that the appropriate variability is present. There is now increasing evidence for this (Bradshaw, 1972).

The experiments throw light on the genetic and physiological character- 
istics of tolerance. Continuous variation has been shown previously; it is demonstrated again here by the range of tolerances found, which correlate with plant height on toxic soil (fig. 5). In all the experiments the numbers of survivors decrease progressivley with increasing concentration of metal and length of time of exposure. If tolerance does show continuous variation, then this would occur if the character had a threshold of expression so that at any one copper level only those individuals with more than a certain tolerance survived. A threshold of expression would occur if tolerance was a mechanism with a finite capacity, i.e. if it could be saturated. It has recently been demonstrated (Peterson, 1969; Turner, 1969, 1970) that tolerance in Agrostis is due to complexing of heavy metals by substances in the cell wall: such a system is likely to have a finite capacity.

It has been clear fro some time that the mechanisms promoting tolerance to different metals are independent from one another both genetically and physiologically. These experiments provide a striking confirmation of this.

Acknowledgments. - Two of us would like to pay tribute to Keith Walley who started the work while he was an undergraduate; by his death a delightful friend and a promising scientist has been lost. We would also like to thank Dr Janis Antonovics who was involved in these experiments from the beginning.

\section{REFERENCES}

ANTONOvics, J., BRADShaW, A. D., AND TURner, R. G. 1971. Heavy metal tolerance in plants. Adv. Ecol. Res., 7, 1-85.

BRADSHAW, A. D. 1972. Some of the evolutionary consequences of being a plant. Evolutionary Biology, 5, 25-47.

BRADSHAW, A. D., MCNEILLY, T., AND GREGORY, R. P. G. 1965. Industrialisation, evolution and the development of heavy metal tolerance in plants. Brit. Ecol. Soc. Symp., 5, 327343.

GARTIDE, D. W., AND MCNEILLY, T. 1974. The potential for evolution of heavy metal tolerance in plants. II. Copper tolerance in normal populations of different plant species. Heredity, 32, 287-297.

GREGORY, R. P. G., AND BRADSHAW, A. D. 1965. Heavy metal tolerance in populations of Agrostis tenuis Sibth. and other grasses. New Phytol., 64, 131-143.

Jowetr, D. 1958. Populations of Agrostis spp. tolerant to heavy metals. Nature, Lond., 182, 816-817.

JOWETT, D. 1964. Population studies on lead tolerant Agrostis tenuis. Evolution, 18, 70-80. MGNEILIY, T., AND BRADSHAW, A. D. 1968. Evolutionary processes in populations of copper tolerant Agrostis tenuis Sibth. Evolution, 22, 108-118.

PEterson, P. J. 1969. The distribution of zinc-65 in Agrostis tenuis Sibth. and A. stolonifera L. tissues. F. Exp. Bot., 20, 863-875.

TURNer, R. G. 1969. Heavy metal tolerance in plants. Brit. Ecol. Soc. Symp., 9, 399-410.

TURNER, R. G. 1970. The subcellular distribution of zinc and copper within the roots of metal tolerant clones of Agrostis tenuis Sibth. New Phytol., 69, 725-731.

URQUHART, G. 1971. Genetics of lead tolerance in Festuca ovina. Heredity, 26, 19-33.

WU, LIN, AND BRADSHAW, A. D. 1972. Aerial pollution and the rapid evolution of copper tolerance. Nature, 238, 167-169. 